\title{
Effects of Lexical Modification on Incidental Vocabulary Acquisition of Iranian EFL Students
}

\author{
Giti Mousapour Negari \\ Department of English Language and Literature, University of Sistan \& Baluchestan, Zahedan, Iran \\ Tel: 98-541-805-2793 E-mail:gmousapour@yahoo.com \\ Mahdieh Rouhi (Corresponding author) \\ Department of English Language and Literature, University of Sistan \& Baluchestan, Zahedan, Iran \\ Tel: 98-937-366-5796_E-mail: rouhimahdieh1@gmail.com
}

Received: February 15, 2012

Accepted: March 1, 2012

Published: June 1, 2012

doi:10.5539/elt.v5n6p95

URL: http://dx.doi.org/10.5539/elt.v5n6p95

\begin{abstract}
The present article reports on the results of a study designed to investigate the effects of two types of lexical modification i.e., lexical simplification and elaboration, on incidental vocabulary acquisition of Iranian EFL learners.To this end, four versions of experimental texts containing 20 target words were created: baseline and simplified versions, as well as elaborated version with two types, i.e., parenthetical elaborated and non-parenthetical elaborated version. ANOVA and Post Hoc analysis were run in order to analyze data obtained from 80 EFL students. Results of two immediate surprise tests, i.e., form recognition test and meaning production test measuring incidental vocabulary learning from modified target words revealed that (a) lexical simplification did not result in incidental vocabulary acquisition (b) both parenthetical and non-parenthetical elaboration were conducive to incidental vocabulary acquisition and (c) comparatively, parenthetical elaborated group outperformed non-parenthetical elaborated group on two incidental vocabulary measures.
\end{abstract}

Keywords: Lexical simplification, Lexical elaboration, Parenthetical elaboration, Non-parenthetical elaboration, Incidental vocabulary acquisition

\section{Introduction}

Language input is apparently a necessary condition for both first and second/ foreign language learning, so considerable attention has been paid to the role of input in second/foreign language learning (Oh, 2001). Reading as a form of language input has been considered as one of the most important skills in the area of language learning and teaching. Accordingly, modifying input with the aim of making it more comprehensible for language learners is of great significance for the ESL as well as EFL researchers.

\subsection{Input Modification}

Krashen's (1994) input hypothesis in the area of second and foreign language learning has been of great importance. Linguistic modification is one of the prevalent phenomena in the first as well as second language acquisition area. In the case of first language acquisition the way adults talk to children namely motherese, or child directed speech is of focal importance in providing them with comprehensible input. Use of exaggerated intonation, slow and clear speech, and grammatical sentences are some of the features of motherese speech (Fromkin, Rodman \& Hyams, 2007).

In this sense adults adjust or modify their speech in a way to be comprehended more by children. In the case of second or foreign language learning a native English speaker interacting with a beginning English learner utilizes "slow rate of speaking, emphasis of key words, common vocabulary, and repetition all are modifications to aid comprehension” (Brewer, 2008, p. 9).

However, as Brewer (2008) stated, for readers in a second language, the written input cannot be negotiated in a similar way as the oral input can be negotiated. As a result, modifying the written input can be one of the ways by which it can be comprehended more by language learners. Or, as Hill (1997) put it, at the level of written texts, input is often modified to make the text more comprehensible, generally in the syntactic structure and the lexicon. 


\subsection{Lexical Simplification and Elaboration}

As Kim (2006) has stated, text modification has two types: elaboration and simplification. He further argued that "text elaboration enriches NS text by providing meanings of unknown words in the form of paraphrases and by making thematic or anaphoric relationships in a text more transparent" (p. 344). Brewer (2008) defined lexical elaboration as "adding a short parenthetical definition (composed of high frequency words) after a low frequency word" (p. 4). While in some other studies it is defined as adding synonyms or definitions in apposition to the difficult lexical items (Kim, 2006). As a result, in order to differentiate between two types of lexical elaboration, the researchers applied the terms "parenthetical elaboration" to refer to the type of elaboration in which appositional synonyms or short definitions are provided within two parentheses; and "non-parenthetical elaboration" to refer to the type of elaboration in which appositional synonyms or short definitions are provided between two commas. Text simplification is defined as "controlling the text targeted at L2 learners by removing unfamiliar linguistic items (e.g., unknown grammatical constructions and lexis) in order to enhance comprehension" (Urano, 2000, p. 4). In lexical simplification, a low frequency word is replaced by a synonymous higher frequency word; or if no one word equivalent is available, replacing a low frequency word with a short phrase consisting of higher frequency words (Brewer, 2008). Therefore, in the process of text elaboration, extra information is added to the text in order to compensate for the linguistic (whether lexical or syntactic) difficulties of the texts. While, in the simplification mechanism, lexical or syntactic complexity is removed from the text.

\subsection{Authentic Texts versus Modified Texts}

As it was mentioned earlier, in the process of text modification some linguistic adaptations will occur in order to make the text easier and comprehensible for the readers. In other words, linguistic authenticity is sacrificed to linguistic simplicity and comprehensibility. The question which may raise here is that whether removal of some complex linguistic structures from authentic material makes unmodified texts anterior to the authentic ones? Are indeed authentic texts superior to the modified ones? Providing appropriate responses for these questions lies in the definition of authenticity.

One of the traditional definitions for the authentic materials is stated by Nunan (1988). He stated that authentic materials are "those which have been produced for purposes other than to teach language" (Nunan 1988, p. 99). In some other definitions authenticity is equated with the traditional notions of authenticity i.e. genuineness of the texts and the real worldliness of the tasks (Long, 1996).

Izumi and Bigelow (2001) stated that if authenticity is defined as genuineness of the text, it undermines the potential of modified input to facilitate language learning. They further argued that, from the psycholinguistic dimensions of authenticity, genuine texts may suffer from lack of learning potential and can indeed be psycholinguistically inappropriate input for the learners (Izumi \& Bigelow, 2001, p. 183). It is also important to recognize that authenticity is a relative construct, or, as Davies (1984) pointed out, "Everything the learner understands is authentic for him" (p. 192).

Rogers and Medley (1988, quoted in Shomoossi \& Ketabi, 2007) contended that the criteria for identifying the authenticity of materials should include the quality, appropriateness and naturalness of the language rather than the source and purpose of the sample. Along the same line, Tweissi (1998) argued that authentic texts are not always the best to give to students who are not ready for them.

According to Guariento and Morley (2001), even authentic materials can be frustrating, confusing and de-motivating if they are too difficult for lower level learners to comprehend, and if there is a mismatch as far as the goals and interests of the learners are concerned. Thus, authentic materials are not always helpful for the students and "just because the materials are authentic, it is no guarantee that the lesson will be successful" (Cardew, 2006, cited in Tatsuki 2006, p. 4).

For readers of low proficiency it is not a good idea to expose them to authentic materials which are far beyond their actual proficiency level. They will be baffled by the syntactic as well as lexical complexities of such texts. Consequently, such complexities may impede them from understanding the text fully. It should be noted that authentic materials are not the only ideal and perfect ones to be used for language learners. It does not mean that we should exclude authentic materials from our pedagogy. Even there might be some modified texts which are not pedagogically appropriate for being used in the class.

In sum, instructional potentiality of modified texts makes them valuable sources in ESL and EFL teaching and learning area since they are lexically and syntactically controlled. It is teachers' task to decide on the use as well as the type of authentic materials or modified ones which are appropriate for their language learners with regard to their students' needs and their proficiency levels. 


\subsection{Lexical Simplification, Elaboration, and Incidental Vocabulary Acquisition}

A number of researches in the domain of text modification have examined the effects of different types of text modification on L2 comprehension (Oh, 2001; Brewer, 2008; Maxwell, 2011). Some other researchers have examined its effect not only on L2 comprehension but also on lexical aspects of language learning (Urano, 2000; Kim, 1996). Konopak (1988) tested the vocabulary learning of fifty five high-ability and average-ability 11 th grade students who read unelaborated and elaborated versions of passages from a history text. Results showed that both the high-ability group and the average-ability group gained substantially more word knowledge from reading the elaborated texts than from reading the original unelaborated texts.

Chung (1995) investigated the incidental vocabulary learning of 9th grade Korean EFL learners who received five versions of an unelaborated original text. The modification types in the study included simplification and elaboration and the combination of the two. It was detected that elaborated groups outperformed the unelaborated one.

A study conducted by Urano (2000), investigated the effects of lexical simplification and elaboration on L2 sentence comprehension and incidental vocabulary acquisition. To this end, forty native speakers of Japanese students were chosen for the study. Forty sentences were created in such a way that one target word was included in each sentence. Three modified versions, i.e., a simplified version, an elaborated version, and a distractor version, of each of these forty sentences were then created. Two surprise vocabulary tests were administered after reading the sentences. i.e., form recognition and meaning recognition tests. Data obtained from these two tests showed that the mean scores in the baseline condition and the elaborated condition were significantly higher than that in the simplified condition. This suggests that presentation of target lexical items can trigger the first step of acquisition, i.e., recognition of form. The mean score in the elaborated condition was slightly higher than the other two, and that in the simplified condition was the lowest. The study concluded that lexical elaboration triggered incidental vocabulary acquisition, while simplification did not; and learners of higher proficiency benefited more from lexical elaboration in terms of the acquisition of word meanings.

Along the same line of research, Kim (2006) examined the effects of input elaboration on vocabulary acquisition through reading. 297 adult Korean EFL non-English major learners at a university in Seoul, Korea were chosen to participate in the study. The baseline i.e., unmodified text was modified in a way that five different types, varying in the combination of two main types of text modification (i.e., lexical elaboration, which was further divided into either an explicit or implicit type, or typographical enhancement) were created. Apart from typographical input enhancement such as use of an attention getting or flagging device to highlight unfamiliar words in the text, lexical elaboration devices used in this study were of two types: explicit and implicit. The most explicit form of lexical elaboration i.e., synonyms or definitions, was chosen in this study and compared to the least explicit form of lexical elaboration i.e., apposition. Results indicated that explicit lexical elaboration was found to have a positive effect on the recognition of word meanings from reading and its positive effect was maintained when typographical enhancement was added. Implicit lexical elaboration was found to have a positive effect on the recognition of word meanings from reading only when typographical enhancement was present. As for form recognition, neither the distinction between explicit and implicit lexical elaboration nor the presence of typographical enhancement made a significant difference.

Moradian and Adel (2011) examined the effects of elaborated texts as well as unelaborated ones on vocabulary acquisition from reading. They designed their study to investigate if explicit and implicit lexical elaborative devices could serve as autonomy enhancing tools which assisted L2 learners in recognizing the meaning of the unknown words in a text in the absence of dictionaries and instructors. The results showed that explicit lexical elaboration, compared to implicit lexical elaboration, was the most effective type of lexical elaboration in the acquisition of L2 lexical items. Along the same line Hajihassani and Porkar (2011) conducted a research on using lexical input modification and typographical enhancement as a tool for improving vocabulary acquisition. The results revealed that lexical and typographical elaboration had an effect on incidental L2 vocabulary learning by Iranian foreign language learners.

Shirinzarii and mardani (2011) attempted to investigate the effects of two types of text modification (simplification and elaboration) on Iranian EFL learners' incidental vocabulary acquisition. The findings revealed that the students who read the elaborated texts had scored the least whereas the scores of the readers of the baseline texts and simplified texts were the highest with a slight superiority of the scores of the former group. Another study conducted by Marefat and Moradian (2008) which investigated the effects of explicit and implicit lexical elaboration devices on the acquisition of L2 vocabulary by Iranian freshman students. The participants were exposed to 26 low-frequency target words by reading one of the three versions of an experimental text containing these words. The results indicated that (a) lexical elaboration devices did not assist in form recognition of L2 vocabulary; (b) lexical 
elaboration devices aided meaning recognition of L2 vocabulary, and (c) neither implicit nor explicit lexical elaboration devices seemed to make a difference in the acquisition of either the forms or meanings of the previously unknown words in the text.

As it was reviewed there are inconsistencies among the results of the studies conducted on incidental vocabulary learning with respect to different types of modification. In some studies the positive effect of input modification has been confirmed whereas in some others the results obtained do not confirm such tendency in terms of acquiring new lexical items. Therefore further research is needed to investigate the nature of input modification. The aim of the present paper is to investigate the effect of lexical modification on Iranian EFL learners' incidental vocabulary acquisition with extreme emphasis on two types of lexical elaboration namely, parenthetical and non-parenthetical elaboration. Hence the following research questions will be addressed in the present study:

1. Is lexical simplification conducive to incidental vocabulary acquisition from reading?

2. Is lexical elaboration conducive to incidental vocabulary acquisition from reading? Which type of lexical elaboration (parenthetical or non-parenthetical) will be more effective (if at all be) in this respect?

\section{Methodology}

\subsection{Participants}

The participants were 80 university students, majoring in English Literature and English Teaching at Azad University of Kerman, Iran. 21 of the subjects were male and 59 of them were female students with an age range of 18 to 26 years old. All the participants' first language was Persian. In order to obtain a homogenized group participants were selected from an initial pool of 120 students who took version 1 of Nation's Vocabulary Levels Test (Nation, 1990). Afterwards, they were divided to four groups of 20 randomly.

\subsection{Material Preparation}

Materials used for this study were adopted from Ackert and Lee (2005). After selecting appropriate reading passages, they went through some adaptation and edition in a way to be tailored for the experimental purposes of the present study. Target words i.e., lexical items, were selected for the research from the selected passages. In order to choose the target words a pilot group of 30 participants were selected. They all had been told to read the passages carefully and underline the words unknown to them-the words they did not know the meaning of. As a result, four versions of experimental texts containing 20 target words were created: baseline and simplified versions, as well as elaborated version with two types, i.e., parenthetical and non-parenthetical elaborated versions.

In the case of lexical simplification, a low frequent lexical item was substituted for another high frequent lexical item in order to make it easier. In the following examples the target word, figure out, in the baseline version was deleted and replaced by the easier one, find out.

Baseline version: ... they are still trying to figure out exactly what it is...

Simplified version: ... they are still trying to find out exactly what it is...

As it is noted above, lexical simplification is led to the deletion of the target word in the baseline version.

Lexical items were either parenthetically elaborated as the example below:

Parenthetical Elaborated version (PE): ... they are still trying to figure out (find out) exactly what it is...

Or, non-parenthetically elaborated as below:

Non-Parenthetical Elaborated version (NPE): ... they are still trying to figure out, find out, exactly what it is...

As it is apparent from provided examples, the difference between these two types of elaboration is the way the synonyms or definitions are provided appositive to the target words. In the case of non-parenthetical elaborated version highly frequent synonyms or definitions are placed between two commas while, they are within two parentheses in the parenthetical elaborated version. To investigate lexical elaboration the researchers of this study decided to design two types of lexical elaboration with respect to different definitions provided in the related area of research.

\subsection{Instruments}

The instruments used in this study are as follows:

\subsubsection{Vocabulary Levels Test (VLT)}

In order to guarantee homogeneity of the subjects participating in the present study a modified version of Nation's (1990) Vocabulary Levels Test was administered. 


\subsubsection{Form Recognition Test}

Since the first step toward learning a vocabulary item is its form, a form recognition test was designed for the study. Acquisition of form is a phenomenon dealing with the physical appearance of words, or acquiring the spelling of the words being encountered (Urano, 2000). Although knowing the form will not guarantee learning the meaning of the word, it is the first stage toward acquiring lexis. In this type of test participants were required to underline the words they had encountered while reading the passages.

\subsubsection{Meaning Production Test}

In order to assess participants' incidental vocabulary learning considering acquisition of meaning, a meaning production test was administered. Participants were presented with a list of all 20 target words which had appeared in the passages. They were required to write the meaning of the words either in English or Persian.

\subsubsection{Prior Knowledge Vocabulary Test}

In order to tackle participants' prior vocabulary knowledge in this study related test was designed to make sure that subjects were not familiar with the chosen target words beforehand. In this type of test participants were asked to identify (circle or underline) the target words they knew before the test. If the number of words previously known by the subjects had affected the overall results of incidental vocabulary gain to a great extent, those items would be deleted from the experiment.

\section{Data Analysis and Results}

The data were analyzed using the one-way ANOVA statistical analysis as performed in the environment of the software SPSS 15.0 for Windows. For all the analyses, the alpha level was set at 0.05 . The reliability index for form recognition and meaning production tests were 0.84 and 0.75 respectively using KR-21 method. The followings are the results of incidental vocabulary acquisition measures:

\subsection{Form Recognition Test}

Table 1 shows mean score and standard deviations for related conditions. As it is indicated, simplified condition has received the lowest mean score among four conditions.

In order to further investigate whether the differences among the means were statistically significant, a one-way ANOVA analysis was performed on the data. Table 3 indicates the significant differences which existed in the performance of the groups. As the results indicate there were significant differences in the mean scores of form recognition test $[\mathrm{F}(3,76)=823.48 ; \mathrm{P}<.05]$. Consequently, the Scheffe method of post-hoc analysis was applied to pinpoint the significant mean differences among four conditions.

The results of post-hoc Scheffe test for form recognition test is presented in Table 4. As it is indicated the mean score of parenthetical elaborated condition was significantly higher than those of other conditions $(\mathrm{M}=17.15$, $\mathrm{P}<0.05)$. The difference in mean scores of parenthetical elaborated and non-parenthetical elaborated groups (1.25) was significant at $\mathrm{P}<0.05$ by 0.02 , signifying that parenthetical elaborated group significantly outperformed non-parenthetical elaborated one in form recognition test. Likewise, parenthetical elaborated group significantly outperformed simplified and baseline groups respectively by 0.000 and 0.03 in the form recognition test. Meanwhile, there was a significant difference between the mean scores of non-parenthetical elaborated and simplified groups (15.40) at $\mathrm{P}<0.05$ by 0.000 .

No significant difference was found between the baseline and non-parenthetical conditions. The mean difference between non-parenthetical elaborated and baseline groups did not reach any significant difference $(-0.05)$. It can be stated that participants' performance in these two groups was approximately similar because the mean difference was trivial. Furthermore, the mean score of baseline condition was significantly higher than that of simplified condition $(\mathrm{M}=15.95, \mathrm{P}<0.05)$.

\subsection{Meaning Production Test}

Table 2 mainly describes the mean scores and their related standard deviation in each condition in meaning production test. By comparison, mean scores in the meaning production test are lower than those of form recognition test.

Results obtained from conducting one-way ANOVA, as it is shown in Table 3, suggested that in meaning production test there existed significant differences in the performance of the four conditions, i.e. parenthetical elaborated, non-parenthetical elaborated, simplified, and baseline groups, $[\mathrm{F}(3,76)=735.75, \mathrm{P}<0.05]$. For further investigation, post hoc Scheffe test was run to identify the significant mean differences.

Table 5 represents the results of post-hoc Scheffe test for meaning production test. Results of paired comparisons of 
meaning production test indicated that parenthetical elaborated group outperformed the other groups significantly $(\mathrm{M}=13.10, \mathrm{P}<0.05)$. Parenthetical elaborated group outperformed non-parenthetical one with a mean difference of 2.75 at 0.000 significant level. Subsequently, the difference in mean scores of parenthetical elaborated group and simplified groups (12.70) was significant at $\mathrm{P}<0.05$ by 0.000 , signifying that parenthetical elaborated group significantly outperformed simplified one in meaning production test. There was a significant mean difference (12.60) between parenthetical elaborated group and baseline group with a significant level of 0.000 . In addition, a significant mean difference (9.95) between non-parenthetical and simplified groups was significant by 0.000 .

Although there was no significant difference between the performance of participants in non-parenthetical and baseline groups in form recognition test, in the meaning production test there was a significant difference (9.85) at $\mathrm{P}<0.05$ by 0.000 . Furthermore, no significant difference was found between the performance of participants in the simplified group and the baseline group $(-0.10)$.

\section{Discussion of the Findings}

\subsection{Research Question 1}

Is lexical simplification conducive to incidental vocabulary acquisition from reading? This question is answered on the basis of the students' performance on form recognition and meaning production tests. Participants' performance in lexically simplified condition on two vocabulary measures did not show any meaningful acquisition of vocabulary. By comparing the results obtained from simplified group with the results of other groups a sharp contrast can be easily noticed. Results showed that lexical simplification did not help learning new lexical items. Such a finding is probably due to the fact that when difficult lexical items are substituted for easier ones acquisition of new lexical items cannot be expected. This finding is consistent with that of Chung's (1995) and Urano's (2000) studies who detected that performance of participants in the lexically simplified condition was lower than that in the elaborated condition. As Oh (2001) in his study pointed out, lexically simplified texts limit learners' exposure to vocabulary and structure in the target language.

Although in the simplified condition neither target words nor synonyms or definitions were supplied, some participants were able to give correct responses in form recognition and meaning production tests. There might have been two potential possibilities for such a finding. This might have been partly due to the participants' background vocabulary knowledge or partly because of the condition under which participants were taking the tests. Since the participants in this group scored approximately zero, such acquisition in this condition can be ignored because it does not change overall results of the study to a great extent. Thus, lexical simplification in the present study did not result in acquiring form and meaning of new lexical items.

\subsection{Research Question 2}

Is lexical elaboration conducive to incidental vocabulary acquisition from reading? Which type of lexical elaboration (parenthetical or non-parenthetical) will be more effective (if at all be) in this respect? To this aim results obtained from form recognition and meaning production tests were analyzed. Participants who read the passages having been lexically elaborated (parenthetical and non-parenthetical elaborated) were able to better perform in two vocabulary measures than the rest. This finding is compatible with the findings of Chung, 1995; Kim, 1996; and Urano, 2000. Chung (1995) investigated the incidental vocabulary learning of 9th grade Korean EFL learners who received five versions of an unelaborated original text. The modification types in the study included simplification and elaboration and the combination of the two. Results showed that all elaborated groups performed better than the unelaborated groups. Kim (1996) demonstrated that college freshman Korean EFL learners who read the lexically elaborated texts performed better on immediate and delayed decontextualized supply-definition posttests than those who read lexically unelaborated texts. The obtained finding in this study also confirms the results of the previous study by Urano (2000) whose study revealed that lexical elaboration triggers incidental vocabulary acquisition. Contrarily, the related finding of this study is in contrast with Kim's (2006) study in which lexical elaboration alone did not result in acquisition of new lexical items.

Thus, as it was discussed earlier no significant difference was detected between the baseline and non-parenthetical conditions. The mean difference between non-parenthetical elaborated and baseline groups did not reach any significant difference. A possible explanation for this finding can be better explained by considering Urano's assertion. He argued that presentation of target lexical items itself can trigger the first stage of acquisition, i.e., recognition of form (Urano, 2000). Since target words were presented in the baseline condition, participants were able to perform in the form recognition test well. Additionally, Long (1996) argued that if both simplification and elaboration enhance comprehension then elaboration is a preferable type of modification since it provides L2 learners with opportunities to learn new linguistic items. Therefore, lexical elaboration was conducive to incidental vocabulary acquisition in this study. 
In order to answer the second part of the related question participants' performance on form recognition and meaning production tests were analyzed. Results indicated that parenthetical elaborated group outperformed non-parenthetical one on the above mentioned tests. An explanation for such a finding can be better provided by considering the experimental conditions for each group. In parenthetical elaborated condition participants read those passages in which synonyms or definitions of the target words were placed between two parentheses. While, in non-parenthetical condition those parentheses were replaced by two commas. It can be said that parentheses might have acted as attention getting devices by help of which participants were able to perform better than the other groups in the study. This finding can be contributed to Schmidt's noticing hypothesis. According to Schmidt's (1994) hypothesis, "noticing is the necessary and sufficient condition for the conversion of input to intake for learning" (p. 17).

To relate the present finding of the research question to that of other studies, experimental conditions of these studies should be taken into account. Most of the studies in the related area have employed implicit and explicit devices (e.g. Silva, 2000; Kim, 2006; Marefat and Moradian, 2008; Moradian and Adel, 2011). As Kim (2006) put it, definitions and synonyms (X, which means, $\mathrm{Y}$ ) are considered as most explicit elaboration devices and apposition $(\mathrm{X}, \mathrm{Y})$ is considered as most implicit elaboration device. In the aforementioned studies explicit lexical elaboration proved to be more effective than the implicit one in the development of vocabulary. Just as Kim (2006) argued "when L2 learners read or listen to a written or spoken text where target words are elaborated by implicit lexical elaboration devices they often do not notice, or take advantage of, those helpful clues" (p. 360), presenting synonyms or short definitions between two commas cannot attract readers' attention as a result they may remain unnoticed. The same thing might have happened to the non-parenthetical condition in the present study. Employing parentheses instead of commas resulted in a better performance in parenthetical condition in both form and meaning tests. What can be inferred from the results of parenthetical elaborated condition is that providing parenthetical synonyms or short definitions appositive to the difficult lexical items could indirectly or better say implicitly direct participants' attention to the form and meaning of new lexical items in the text.

\section{Conclusion and Implications}

The present study was an attempt to investigate the effect of lexical modification on incidental vocabulary acquisition of Iranian EFL learners. Moreover, it was designed to investigate lexical elaboration at a deeper level than that of previous studies. To this aim, lexical elaboration was divided into two types, i.e. parenthetical elaboration and non-parenthetical elaboration. The results suggested that a) lexical simplification was not conducive to incidental vocabulary acquisition b) lexical elaboration had a significant role in acquiring new lexical items incidentally from reading texts, and c) comparatively, participants who read the texts having been parenthetically elaborated could significantly outperform those reading non-parenthetically elaborated texts. Generally speaking, what can be concluded from the obtained results of the present study is that the related findings have proved the superiority of elaboration over simplification and also the superiority of parenthetical elaboration over non-parenthetical elaboration.

The present study has pedagogical implications for EFL learners, material designers, and also EFL teachers. Supplying synonyms or short definitions exactly next to the lexical items can help the learners acquire the second stage of vocabulary learning, meaning acquisition, easier. On the other hand, designing reading materials for language learners in a way that students face target words repeatedly throughout reading is of great importance. Teachers whose attempt is to help students improve their vocabulary knowledge can best make use of input elaboration. Language teachers might find the results of this study useful in that it provides an alternative way of teaching vocabulary in addition to other ways of teaching vocabulary such as lexical inferencing, mnemonic techniques, or key word methods.

\section{References}

Ackert, P., \& Lee, L. (2005). Concepts and comments. USA: Thomson.

Brewer, B. (2008). Effects of lexical simplification and elaboration on ESL readers' local-level perceived comprehension (Master's thesis). Available from ProQuest Dissertations and Theses database.

Chung, H. (1995). Effects of Elaborative Modification on Second Language Reading Comprehension and Incidental Vocabulary Learning (Unpublished master's thesis). University of Hawai'i at Manoa, USA.

Davies, A. (1984). Simple, simplified, and simplification: what is authentic? In J.C. Alderson \& A.H. Urquart (Eds.), Reading in a foreign language. pp. 181-198. London: Longman.

Fromkin, V., Rodman, R., \& Hyams, N. (2007). An introduction to language. USA: Thomson.

Guariento, W., \& Morely, J. (2001). Text and task authenticity in the EFL classroom. ELT Journal, 55(4), 374-353. 
http://dx.doi.org/10.1093/elt/55.4.347

Hajihassani, H., \& Porkar, R. (2011). Using lexical input modification and typographical enhancement as a tool for improving Iranian foreign language learner's vocabulary learning through reading. Paper presented in the 2011 international conference of ICT for Language Learning. Retrieved $15^{\text {th }}$ December, 2011 from pixel-online.net/ICT4LL2011/accepted abstract.php

Hill, D. R. (1997). Graded readers. ELT Journal, 51(1), 57-79.

Izumi, S., \& Bigelow, M. (2001). Methodological and theoretical issues in testing the effects of focus on form. TESOL Quarterly, 35(1), 181-189. http://dx.doi.org/10.2307/3587866

Kim, Y. (1996). Effects of text elaboration on intentional and incidental foreign language vocabulary learning. (Unpublished master's thesis), University of Hawai'i at Manoa, USA.

Kim, Y. (2006). Effects of input elaboration on vocabulary acquisition through reading by Korean learners of English as a foreign language. TESOL Quarterly, 40(2), 341-373. http://dx.doi.org/10.2307/40264526

Konopak, B. C. (1988). Effects of Inconsiderate vs. Considerate Text on Secondary Students' Vocabulary Learning. Journal of Reading Behavior, 20, 25-41.

Krashen, S. (1994). The input hypothesis and its rivals. In N. Ellis (Ed.), Implicit and explicit learning of languages. (p. 45-77). London: Academic Press.

Long, M. H. (1996). The role of the linguistic environment in second language acquisition. In W. C. Ritchie \& T. K. Bhatia (Eds.), Handbook of second language acquisition (pp. 413-468). San Diego: Academic Press.

Marefat, F., \& Moradian, M. R. (2008). Effects of Lexical Elaborative Devices on L2 Vocabulary Acquisition: Evidence from Reading. The Journal of Teaching English Language and Literature Society of Iran, 2(6), 101-124.

Maxwell, S. (2011). The effects of two types of text modification on English language learners' reading comprehension: simplification versus elaboration (Master's thesis). University of Hamline, Minesota.

Moradian, M. R., \& Adel, M. R. (2011). Explicit Lexical Elaboration as an Autonomy Enhancing Tool for Acquisition of L2 Vocabulary from Reading. Journal of Studies in Literature and Language 3(3), 153-159. http://dx.doi.org /10.3968/j.sll.1923156320110303.143

Nation, P. (1990). Teaching and learning vocabulary. Boston: Heinle \& Heinle.

Nunan, D. (1988). The learner-centered curriculum. Cambridge: Cambridge University Press.

Oh, S. (2001). Two types of input modification and EFL reading comprehension: Simplification versus elaboration. TESOL Quarterly, 35(1), 69-96. http://dx.doi.org /10. 2307/3587860

Schmidt, R. (1994). Implicit learning and the cognitive unconscious of artificial grammars and SLA. In N. Ellis (Ed.), Implicit and explicit learning of languages (pp. 165-209). London: Academic Press.

Shirin Zarii, M., \& Mardani, M. (2011). Two Types of Text Modification and Incidental Vocabulary Acquisition: Simplification vs. Elaboration. The Iranian EFL Journal, 7(1), 127-156

Shomoossi, N., \& Ketabi, S. (2007). A Critical look at the concept of authenticity. Electronic Journal of Foreign Language Teaching, 4(1), 149-155. Retrieved September, 12, 2011 from http://e-flt.nus.edu.sg/v4n12007/shomoossi.pdf

Silva, A. D. (2000). Text Elaboration and Vocabulary Learning (Unpublished master's thesis). University of Hawai'i at Manoa, USA.

Tatsuki, D. (2006). What is authenticity? The Language Teacher, 16(5), 17-21. Retrieved May 1, 2011, from http://jalt.org/pansig/2006/HTML/Tatsuki.htm

Tweissi, A. I. (1998). The effects of the amount and the type of simplification on foreign language reading comprehension. Reading in a Foreign Language, 11, 191-206.

Urano, K. (2000). Lexical simplification and elaboration: sentence comprehension and incidental vocabulary acquisition (Unpublished Master's thesis). University of Hawai'i at Manoa, Honolulu. 
Table 1. Form recognition test Means and Standard Deviations $(\mathrm{n}=80)$

\begin{tabular}{|c|c|c|c|}
\hline conditions & $\mathrm{K}$ & $\mathrm{M}$ & $\mathrm{SD}$ \\
\hline parenthetical elaborated & 20 & 17.15 & 1.13 \\
\hline non-parenthetical elaborated & 20 & 15.90 & 1.33 \\
\hline simplified & 20 & 0.50 & 0.51 \\
\hline baseline & 20 & 15.95 & 1.66 \\
\hline
\end{tabular}

Table 2. Meaning production test Means and Standard Deviations $(\mathrm{n}=80)$

\begin{tabular}{|c|c|c|c|}
\hline conditions & $\mathrm{K}$ & $\mathrm{M}$ & $\mathrm{SD}$ \\
\hline parenthetical elaborated & 20 & 13.10 & 1.16 \\
\hline non-parenthetical elaborated & 20 & 10.35 & 1.56 \\
\hline simplified & 20 & 0.40 & 0.68 \\
\hline baseline & 20 & 0.50 & 0.68 \\
\hline
\end{tabular}

Table 3. One-way ANOVA for form recognition and meaning production tests

\begin{tabular}{|c|c|c|c|c|c|c|}
\hline \multirow{4}{*}{$\begin{array}{l}\text { Form } \\
\text { recognition } \\
\text { test }\end{array}$} & source & SS & $\mathrm{df}$ & MS & $\mathrm{F}$ & Sig \\
\hline & $\begin{array}{l}\text { Between } \\
\text { groups }\end{array}$ & 3780.45 & 3 & 1260.15 & 823.48 & $0.000 *$ \\
\hline & Within groups & 116.30 & 76 & 1.53 & & \\
\hline & Total & 3896.75 & 79 & & & \\
\hline \multirow{3}{*}{$\begin{array}{l}\text { Meaning } \\
\text { production } \\
\text { test }\end{array}$} & $\begin{array}{l}\text { Between } \\
\text { groups }\end{array}$ & 2618.23 & 3 & 872.74 & 735.75 & $0.000 *$ \\
\hline & Within groups & 90.15 & 76 & 1.18 & & \\
\hline & Total & 2708.38 & 79 & & & \\
\hline
\end{tabular}

Table 4. Scheffe test for form recognition test

\begin{tabular}{|c|c|c|c|c|}
\hline \multirow{2}{*}{ Group } & Group & Mean difference & Mean & Sig \\
\hline PE & NPE & 1.25 & 17.15 & $0.02^{*}$ \\
& Simplified & 16.65 & & $0.000^{*}$ \\
& Baseline & 1.20 & & $0.03^{*}$ \\
\hline NPE & PE & -1.25 & 15.90 & $0.02^{*}$ \\
& Simplified & 15.40 & & $0.000^{*}$ \\
& Baseline & -0.05 & & 0.99 \\
& & -16.65 & 0.50 & $0.000^{*}$ \\
& PE & -15.40 & & $0.000^{*}$ \\
& NPE & -15.45 & & $0.000^{*}$ \\
\hline Bimplified & Baseline & -1.20 & 15.95 & $0.03^{*}$ \\
& PE & 0.05 & & 0.99 \\
& NPE & 15.45 & & $0.000^{*}$ \\
\hline
\end{tabular}

PE: Parenthetical Elaboration

NPE: Non-Parenthetical Elaboration 
Table 5. Scheffe test for meaning production test

\begin{tabular}{|c|c|c|c|c|}
\hline \multirow{2}{*}{ Group } & Group & Mean difference & Mean & Sig \\
\hline \multirow{2}{*}{ PE } & NPE & 2.75 & 13.10 & $0.000^{*}$ \\
& Simplified & 12.70 & $0.000^{*}$ \\
& Baseline & 12.60 & & $0.000^{*}$ \\
& & & & $0.000^{*}$ \\
& PE & -2.75 & 10.35 & $0.000^{*}$ \\
& Simplified & 9.95 & & $0.000^{*}$ \\
& Baseline & 9.85 & & $0.000^{*}$ \\
& & & & $0.000^{*}$ \\
& PE & -12.70 & & 0.99 \\
\hline Simplified & NPE & -9.95 & & $0.000^{*}$ \\
& Baseline & -0.10 & & $0.000^{*}$ \\
\hline
\end{tabular}

PE: Parenthetical Elaboration

NPE: Non-Parenthetical Elaboration 